\title{
WHEEL-RAIL WEAR INVESTIGATION ON A HEAVY HAUL BALLOON LOOP TRACK THROUGH SIMULATIONS OF SLOW SPEED WAGON DYNAMICS
}

\author{
Yan Quan SUN*, Maksym SPIRYAGIN, Colin COLE, Dwayne NIELSEN \\ Centre for Railway Engineering, Central Queensland University, Rockhampton, Australia \\ Received 9 September 2016; revised 12 January 2017; accepted 1 February 2017; \\ published online 4 September 2017
}

\begin{abstract}
Heavy haul railway track infrastructure are commonly equipped with balloon loops to allow trains to be loaded/unloaded and/or to reverse the direction of travel. The slow operational speed of trains on these sharp curves results in some unique issues regarding the wear process between wheels and rails. A wagon dynamic system model has been applied to simulate the dynamic behaviour in order to study the wheel-rail contact wear conditions. A wheelrail wear index is used to assess the wear severity. The simulation shows that the lubrication to reduce the wheel-rail contact friction coefficient can significantly reduce the wear severity. Furthermore, the effects of important parameters on wheel-rail contact wear including curve radius, wagon speed and track superelevation have also been considered.
\end{abstract}

Keywords: balloon loop track, wagon dynamics, wheel-rail wear index, simulation.

\section{Introduction}

Balloon loops are quite common in Australian heavy haul railway networks, which are equipped to allow heavy haul trains (Spiryagin et al. 2016) to be loaded/ unloaded and to reverse the direction of travel without having to shunt or stop the train. Due to the characteristic of balloon loops with some severe sharp curves, the slow operational speed of heavy haul trains is necessary. The increasing competition driven by international markets have forced Australian heavy haul industries to operate with greater axle loads and longer trains than originally designed, but the corresponding track systems, especially rails, have not been upgraded, and an equivalent increase in maintenance effort has not occurred. These additional demands on the track can accelerate the deterioration of rails. The issues regarding the wear between wheel and rail and the Rolling Contact Fatigue (RCF) damage on wheel and rail surfaces have been a concern with the rail operators. Currently, the most common maintenance strategies to manage the rail-wheel contact on curved tracks are through lubrication and Rail Grinding (RG) (Spiryagin et al. 2014).

There is a good correlation among the type of damage (head checks, spalling marks), the number of RG operations, the profile of the rail, the curve radius and curve's superelevation. The number of RG operations in- creased with higher superelevations and decreased with larger curve radii (Cuervo et al. 2015). A rail passenger vehicle model was used to examine the wheel damage mechanism on three typical curved tracks (Tao et al. 2013). The results indicate that the total creep force on the wheel of leading wheelset on the low rail of a curved track points to the third quadrant of the Cartesian coordinate system. The creep force easily results in RCF cracks on the wheel surface and their directions are approximately perpendicular to the creep force. As the curve radius decreases, the total creep force observably increases. The effect of curve radius on the wear and RCF of wheel steels under dry conditions was investigated on a wheel-rail testing machine (He et al. 2014). The results indicated that with a decrease in curve radius the following effects occurred; the wear volume of wheel steels increased, the plastic flow layer became thicker and uneven, and the fatigue crack propagation of wheel steel intensified.

Generally, a balloon loop is a railway track that consists of a group of sharp curves with different radii. Therefore, the wagon dynamics on a balloon loop is similar to that in a sharp curved track. When a wagon is negotiating a curved track, the wheelset movement and the wheel-rail contact will change noticeably. This change can intensify the wagon and track dynamic in-

${ }^{*}$ Corresponding author. E-mail: y.q.sun@cqu.edu.au 
teractions leading to severe rail damage and potential wagon derailment due to the severe change of track alignment and geometry with or without the presence of rail defects (Remennikov, Kaewunruen 2008). On sharp curved tracks, a common defect that may occur on the low rail is the spalling defect which is mainly formed in the centre of rail top. On the high rail, severe side wear and plastic flow may occur, and the profile changes conforming to the flange shape mostly due to the effect of wheel sliding. Sometimes, RCF defects develop on the gauge corner of the high rail mostly due to the effect of high contact stresses. The initial stage of RCF is identified with gauge corner checking cracks which increase in size and develop into intermediate and severe stages of checking cracks and spalling. Rail corrugations may also appear on curved tracks. The influence of different radius and superelevation parameters on the rail corrugation was analysed (Sun, Simson 2008) and the results showed that the radius size was a larger factor, while the influence of superelevation was not obvious. In general, smaller radius curved tracks result in flange wear, while more moderate radius ones result in RCF defects. There is a correlation between wear rates and RCF defects, high wear rates may reduce RCF defects and vice versa. Currently, the studies on the wheel-rail dynamic interaction of curved track are not rigorously and systematically performed (Wang et al. 2014). Currently, the accepted approaches to prevent or minimise rail damage are by the application of RG and/or lubrication.

An optimisation strategy for the design of RG profiles to be used on heavy-haul railway curves was suggested by Zhai et al. (2014). The authors claimed the wheel-rail dynamic interactions were clearly improved and the rail side wear was alleviated by $30-40 \%$ when using new grinding profile. This was accomplished by first increasing the Rolling Radius Difference (RRD) between the high and low wheels to a value as large as possible which improved the creep steering ability, thus reducing both the wheelset attack angle and the side wear. Secondly, matching the wheel and rail profile reduces the wheel-rail contact stress, thus mitigating the RCF defects.

Rail lubrication of curves was widely introduced in Sweden during the 1970's to reduce the high wear rate of gauge faces in sharp curved tracks. The first tests performed in Sweden showed that lubrication decreased wear rates by roughly 10 times (Waara et al. 2004). Preventive grinding in combination with lubrication has been the most efficient way to avoid fast degrading of curved rail track. As lubrication is often applied on the high rail to reduce wear, the creep force on the high rail becomes saturated and this may drive the wheel-rail contact on the low rail into a roll-slip oscillation (Torstensson, Nielsen 2011). Field test results show that top of rail lubrication on the low rail has the effect of greatly reducing lateral force, and sliding between wheel and rail could be significantly reduced. High rail gauge corner lubrication increases lateral force and decreases the kinetic friction coefficient (Ishida, Aoki 2004).
In this paper, the GENSYS (DEsolver 2017) multibody software is used to simulate wagon dynamic behaviours in order to investigate the wheel-rail wear damage on a balloon loop track. The effect of curve radius, curve cant and speed on the wheel-rail wear are examined. Solutions to reduce the wheel-rail wear are suggested.

\section{Wheel-rail wear}

To investigate the mechanisms behind wheel-rail RCF and wear, a lot of the theoretical studies and experiments have been conducted. Wheel-rail contact wear was simulated using Archard's law (Telliskivi, Olofsson 2004). Archard's law is applicable only in the slip region of the contact patch and assumes that the volume of worn material $V_{\text {wear }}\left[\mathrm{m}^{3}\right]$ is proportional to the normal contact force $N[\mathrm{~N}]$ and the sliding distance $d[\mathrm{~m}]$, and inversely proportional to the hardness $H\left[\mathrm{~N} / \mathrm{m}^{2}\right]$ of the softer of the two materials in contact. The amount of wheel-rail contact wear is calculated using Archard's law combined with FASTSIM (Johansson et al. 2011). To obtain the wear model, that is the dependence of the wear rate from the contact parameters, simulation of wear between wheel flange and side face of the railhead when a vehicle moving in a curve was used. Performing such simulation requires similarities of wear mechanisms characterized by the wear rate, worn surface features, size, morphology, and colour of wear debris. The wear rate was studied as a function of $p \cdot \lambda$ parameter, where $\mathrm{p}$ is the contact pressure $[\mathrm{MPa}]$ and $\lambda$ is the relative slippage (Zakharov, Zharov 2002). Wear was investigated in terms of wear rate under different working conditions (Donzella et al. 2005). The physical understanding of wear mechanisms is, however, far from a mathematical description of the damage rate.

Different from the definition of the wear rate, for wheel-rail wear prediction, the wear number $T_{\gamma} / A$ was first introduced by the early British Rail researchers (Harvey, McEwen 1986), who defined it as the energy expended per unit distance travelled calculated for each wheel-rail contact $\left(T_{\gamma} / A\right.$, where: $A$ is the wheel-rail contact patch area $\left.\left[\mathrm{mm}^{2}\right]\right) . T_{\gamma}$ was defined as the dot product of creep force and creepage $[\mathrm{J} / \mathrm{m}]$ or $[\mathrm{N}]$ (Resonate Group Ltd 2016) based on the experimental work, which has shown that the amount of metal removed through wear is proportional to the energy expended in the wheel-rail contact. The wear of wheel-rail contact can therefore be studied by calculating the wear number $T_{\gamma} / A$ for a range of curve radii representing the conditions on a real railway line. Therefore, a wear index can be defined, which is related to the $T_{\gamma}$ (Resonate Group Ltd 2016) as follows:

$$
\text { Wear Index }=\left\{\begin{array}{lll}
T_{\gamma} \cdot 0.005 & - \text { for mild wear, } & T_{\gamma}<160 ; \\
T_{\gamma} \cdot 0.025-3.2 & - \text { for severe wear, } & T_{\gamma} \geq 160 .
\end{array}\right.
$$

Based on the $T_{\gamma}$, the wheel profile wear can be predicted (Pearce, Sherratt 1991). From the time history of the response, the position of the contact on the 
wheel and the wheel-rail creep forces and creepages are correlated and summed to give a material loss distribution across the wheel profile and hence a small change in profile shape. The optimal design of wheel profile for railway vehicles considered the minimum wear of wheels, rails and stability of wheelset and cost efficiency of design (Shevtsov et al. 2005), in respect of $T_{\gamma}$. A new wear map to improve the wear index in higher stresses and slips was developed to predict wheel profile evolution due to wear (Braghin et al. 2006).

Wheel-rail contact wear has been a great concern of the railway industries around the world and the cost of rail replacement and repairs due to wear and RCF has been great. For example, the railroad industry in the United States of America spends approximately $\$ 2$ billion USD annually on rail replacement and repairs (Hernández et al. 2007).

\section{Multi-body rail wagon modelling}

A typical freight wagon model from GENSYS (Sun et al. 2011, 2012) is shown in Figure 1. This model includes 11 masses - one wagon car body, 2 bolsters, 4 sideframes and 4 wheelsets, which are modelled as rigid bodies with

a)

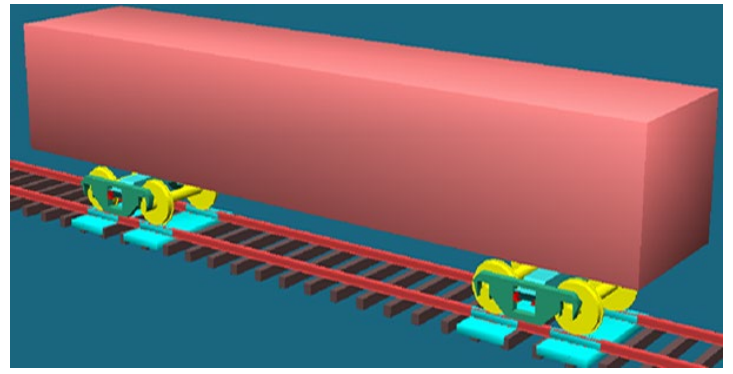

six degrees of freedom. The basic wagon parameters are given in Table.

A new wheel profile called WPR 2000 (ESR 0332:2010) and a new rail profile called AS60 (EMRAILS 2016) are selected, as shown in Figure 2. The profiles are popular with railway organisations in Australia.

\subsection{Connection between wagon car body and two bogies}

Centre bowl torsional friction is modelled as four vertical $(Z)$ stiffness elements associated with a two-dimensional $(X-Y)$ friction block at each stiffness element. Centre bowl rim friction is modelled by two longitudinal $X$ stiffness elements associated with one-dimensional $(Y)$ friction block at each stiffness element. Lateral constraint is modelled by one lateral stiffness element and material damping is modelled by one three-dimensional damper.

\subsection{Connection of side bearer between wagon car body and bolster}

One vertical $(Z)$ damping element and one vertical $(Z)$ stiffness element associated with two-dimensional $(X-Y)$ horizontal friction block.

b)

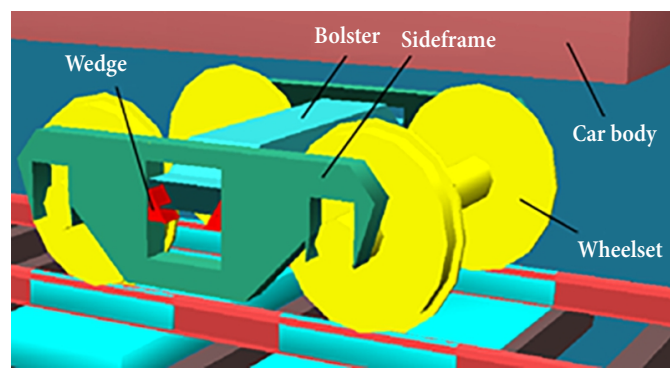

Figure 1. Modelling of a typical heavy haul wagon in GENSYS: a - wagon model; b - bogie model

Table. Wagon basic data

\begin{tabular}{|c|c|c|c|c|c|c|c|}
\hline \multirow{2}{*}{ Component } & \multirow{2}{*}{ Mass $[\mathrm{kg}]$} & \multicolumn{3}{|c|}{ Mass moment of inertia $\left[\mathrm{kg} \cdot \mathrm{m}^{2}\right]$} & \multicolumn{3}{|c|}{ Mass centre coordinates $[\mathrm{m}]$} \\
\hline & & $I_{x x}$ & $I_{y y}$ & $I_{z z}$ & $X$ & $Y$ & $Z$ \\
\hline \multicolumn{8}{|c|}{ Wagon } \\
\hline Empty & 10201.8 & 22900 & 318320 & 321540 & 0 & 0 & -1.611 \\
\hline Loaded & 117400 & 181240 & 1550960 & 1584350 & 0 & 0 & -2.325 \\
\hline \multicolumn{8}{|c|}{ Bogie 1} \\
\hline Wheelset 1 & 1731.8 & 514 & 135.8 & 514 & 6.82 & 0 & -0.46 \\
\hline Wheelset 2 & 1731.8 & 514 & 135.8 & 514 & 4.99 & 0 & -0.46 \\
\hline Sideframe $1 \mathrm{r}$ & 816.3 & 133 & 208.2 & 184 & 5.905 & 1.0033 & -0.468 \\
\hline Sideframe 11 & 816.3 & 133 & 208.2 & 184 & 5.905 & -1.0033 & -0.468 \\
\hline Bolster 1 & 1103.9 & 400.1 & 40.3 & 230.7 & 5.905 & 0 & -0.48 \\
\hline \multicolumn{8}{|c|}{ Bogie 2} \\
\hline Wheelset 3 & 1731.8 & 514 & 135.8 & 514 & -4.99 & 0 & -0.46 \\
\hline Wheelset 3 & 1731.8 & 514 & 135.8 & 514 & -6.82 & 0 & -0.46 \\
\hline Sideframe $2 \mathrm{r}$ & 816.3 & 133 & 208.2 & 184 & -5.905 & 1.0033 & -0.468 \\
\hline Sideframe 21 & 816.3 & 133 & 208.2 & 184 & -5.905 & -1.0033 & -0.468 \\
\hline Bolster 2 & 1103.9 & 400.1 & 40.3 & 230.7 & -5.905 & 0 & -0.48 \\
\hline \multicolumn{8}{|c|}{ Total wagon weight } \\
\hline
\end{tabular}

\begin{tabular}{|l|c|}
\hline Empty & 22602 \\
\hline Loaded & 140002 \\
\hline
\end{tabular}




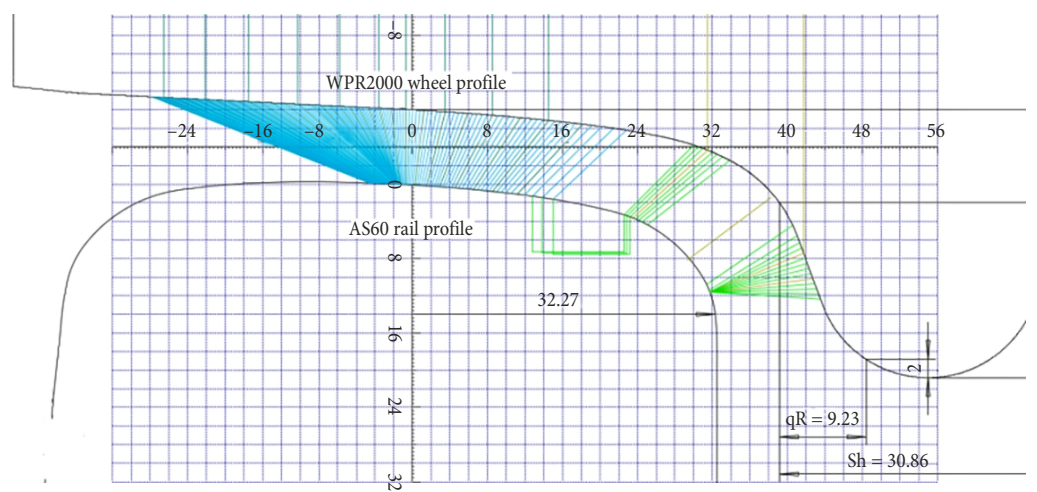

Figure 2. Wheel and rail profiles

\subsection{Secondary suspensions}

Each secondary suspension between bolster and sideframe is considered. The spring nest is modelled as two vertical $(Z)$ coil-springs in parallel with the longitudinal distance of $0.28 \mathrm{~m}$ and two corresponding threedimensional damping elements. Longitudinal constraint is provided by one longitudinal $(X)$ bumpstop. Lateral constraint is provided by one lateral $(Y)$ bumpstop. Each friction wedge between bolster and sideframe is modelled as a massless block and the exact triangle shape is considered.

\subsection{Primary suspensions}

The primary suspension is modelled as two vertical $(Z)$ contact stiffness elements laterally separated by $120 \mathrm{~mm}$ on each axle box. The separation provides roll stiffness to side-frame and yaw friction moment, which is associated with one two-dimensional $(X-Y)$ horizontal friction block at each element. One three-dimensional $(X-$ $Y-Z$ ) viscous damping element is included in the model together with one longitudinal bumpstop and one lateral bumpstop.

\subsection{Wheel-rail contact}

A standard function in GENSYS (DEsolver 2017) was used for the modelling of a wheel-rail contact interaction as shown in Figure 3. Three springs represent three contact points such as top of rail $c p 1$; gauge corner $c p 2$

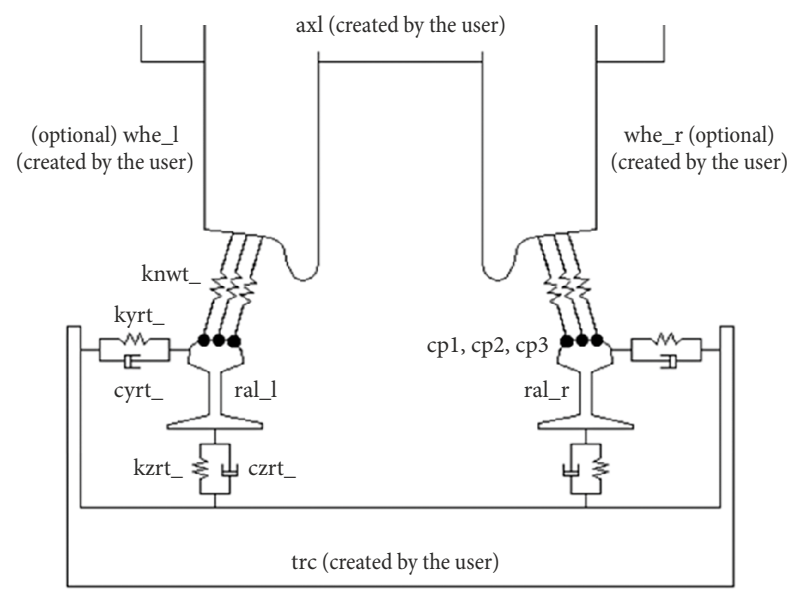

Figure 3. Wheel-rail contact in GENSYS and gauge face $c p 3$ contacts. These three different contact points can be in contact simultaneously. The calculations of creep forces are made in a lookup table calculated by Fasim. The coefficient of friction for dry conditions was assumed to be 0.5 based on an AAR/TTCI study (Chiddick, Eadie 1999). In GENSYS, the equation cpa_\$1. Fnu $=$ creep $\times$ creep force, which is the sum of all contact surfaces, is sometimes denoted $T_{\gamma}[\mathrm{J} / \mathrm{m}]$ or $[\mathrm{N}]$. However, the spin and spin moment can be calculated in GENSYS, therefore, in this paper, the calculated $T_{\gamma}$ includes spins $\times$ spin moments at three contact surfaces $\# 1$, \#2 and \#3.

The output $T_{\gamma}$ in Equation (1) from GENSYS for a wheel-rail contact can be expressed as:

$$
\begin{aligned}
& T_{\gamma}=\sum\left(T_{y i} \cdot \gamma_{y i}+T_{x i} \cdot \gamma_{x i}+M_{z i} \cdot \omega_{z i}\right), \\
& i=c p 1, c p 2, c p 3
\end{aligned}
$$

where: $T$ and $M$ are the longitudinal/lateral creep force and spin creep moment components at a contact point; $\gamma$ and $\omega$ are the longitudinal/lateral and spin creepage components at a contact point. The output $T_{\gamma}$ will be the sum of all contact points.

The above vehicle model can be considered to be reliable because it was generated based on a GENSYS rail vehicle model, which was compared and validated during Manchester Benchmark tests.

\section{Hypothetical track (balloon loop)}

A hypothetical balloon loop track layout is shown in Figure 4.

In Figure 4, the balloon loop track is comprised of four curved sections, with the curve radii being 495 , 200, 300 and $400 \mathrm{~m}$. The track is standard gauge with a cant of $0 \mathrm{~mm}$, and was considered as an ideal loop track without track irregularities. Only dry condition was evaluated for the three wheel-rail contacts using a friction coefficient of 0.5 . The hypothetical balloon loop track was assumed as a new track. Therefore, no track irregularities were considered in the paper. Because the operational speeds on the balloon loop are very low, the implementation of track irregularities would not lead into significant changes in results. 
a)

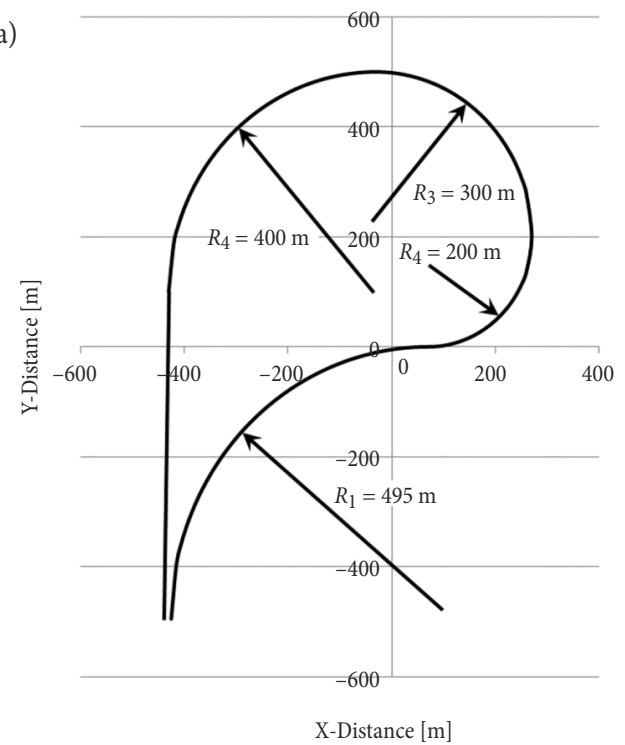

b)

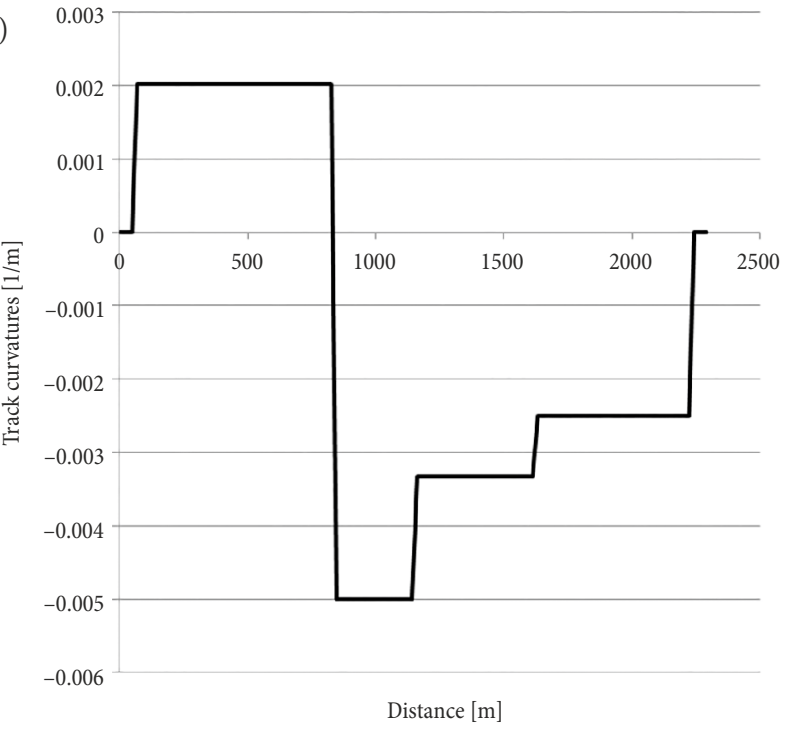

Figure 4. A hypothetical balloon loop layout: $\mathrm{a}$ - layout; $\mathrm{b}$ - track curvature

\section{Simulations and Results}

The simulations are conducted with the comprehensive wagon model described in Section 3 and running on the balloon loop track described in Section 4. Starting from the curve with $R_{1}=495 \mathrm{~m}$ and finishing the curve with $R_{4}=400 \mathrm{~m}$ at the low speeds, e.g., 5, 10 and $15 \mathrm{~km} / \mathrm{h}$. The simulation results in the wear index for every wheel-rail contact described in Equation (1). Figure 5 shows the wear indexes on all wheel-rail contacts of the wagon at the speed of $10 \mathrm{~km} / \mathrm{h}$. The left graph shows the wear indexes on the leading bogie while the right graph shows the wear indexes on the trailing bogie. $B 1$ and $B 2$ represent the leading and trailing bogies, $W 1$ and $W 2$ represent the leading and trailing wheelsets in a bogie, and $R$ and $L$ represent the right and left wheels on a wheelset. From the left graph of Figure 5, the high rail on the curve with radius $R_{1}=495 \mathrm{~m}$, both high and low rails on the curves with radii $R_{2}=200 \mathrm{~m}$ and $R_{3}=300 \mathrm{~m}$, and the high rail on the curve with radius $R_{4}=400 \mathrm{~m}$ are suffered from the severe wear as the wear indexes on these rails are greatly larger than $0.8-(160 \times 0.025-3.2=0.8$ based on Equation (1)). The high rail wear is very severe because the high rail usually has two or three point contacts, causing severe gauge corner wear. From the right graph of Figure 5, it can be seen that the wear indexes caused by the trailing bogie are much smaller than those by the leading bogie.

Based on Figure 5, it can be observed that the wear indexes on each wheelset are quite different. Generally, the leading wheelset on each bogie plays a significant role on the wheel-rail contact wear damage. Generally, on the curve with smaller radius, a larger wear index on each wheelset occurs. However, due to the wagon dynamic behaviours during curving, the wear index on the right wheel of trailing wheelset on the trailing bogie is smaller on the curve with radius $R_{2}=200 \mathrm{~m}$ than those on the curves with radii $R_{3}=300 \mathrm{~m}$ and $R_{4}=400 \mathrm{~m}$ from the right graph of Figure 5.
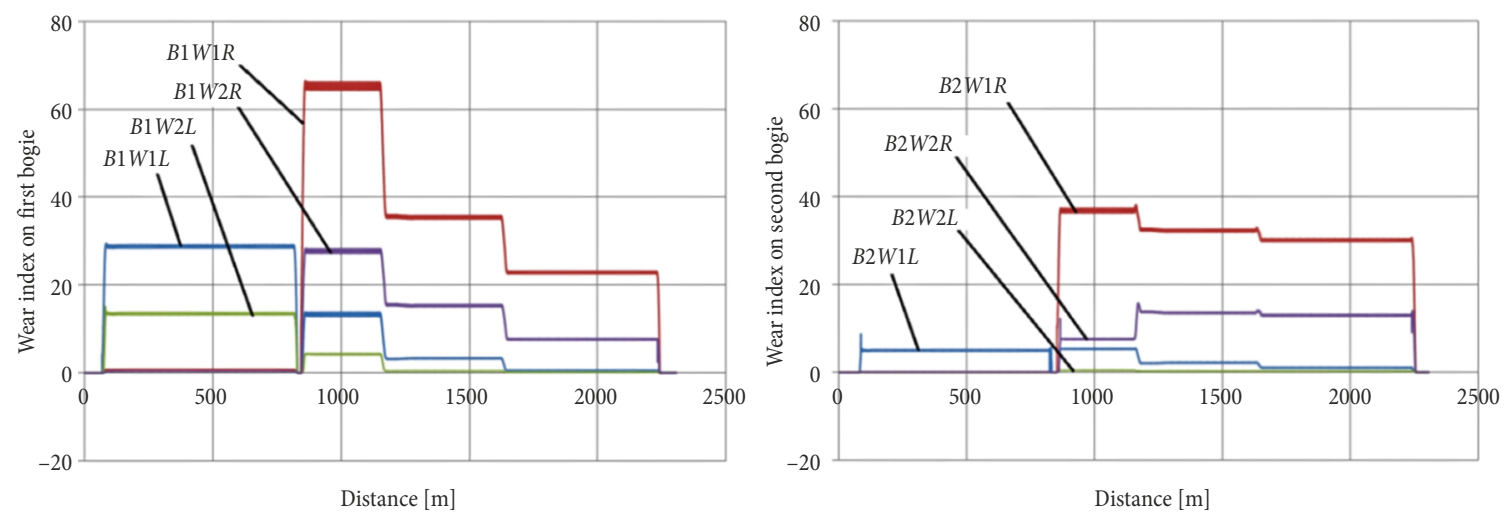

Figure 5. Wear indexes on all wheel-rail contacts (in the output graph - B1 and $B 2$ : leading and trailing bogies; $W 1$ and $W 2$ : leading and trailing wheelsets in a bogie; $R$ and $L$ : the right and left wheels on a wheelset; $B 1 W 1 R$ - the right wheel of the first wheelset in the leading bogie) 


\subsection{Effect of curve radius}

In order to visualise the overall effect of track curve on the wheel-rail contact wear, the relationship between the sum of wear indexes on all wheelsets of both bogies on a curve and the curve radius is plotted and shown in Figure 6.

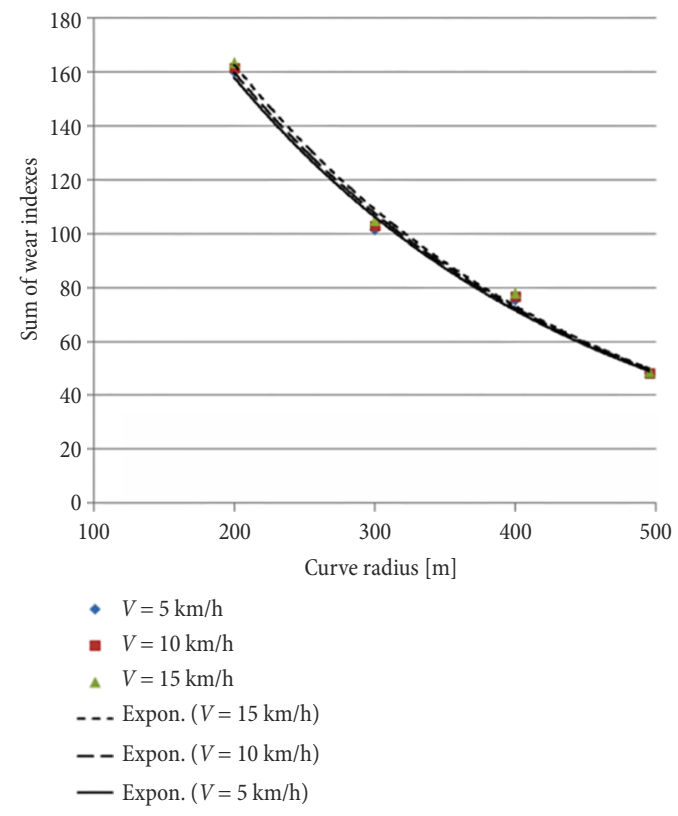

Figure 6. Sum of wear indexes and curve radius

From Figure 6, if the curve radius is reduced from 400 to $300 \mathrm{~m}$, the sum of wear indexes is increased by $34 \%$ while if it is from 300 to $200 \mathrm{~m}$, the sum of wear indexes is increased by $56 \%$.

\subsection{Effect of wagon speed}

Because the operation of a train on a balloon loop track is required at the low speed, the wagon speed in the study is limited to speeds under $15 \mathrm{~km} / \mathrm{h}$. Hence, the simulations at the speeds of 5,10 and $15 \mathrm{~km} / \mathrm{h}$ are conducted, and the wear indexes for all wheels on the $200 \mathrm{~m}$ radius curve are shown in Figure 7.

The comparative wear indexes on the $200 \mathrm{~m}$ radius curve for the leading and trailing bogies are pro- vided in Figure 7. From Figure 6, it can be observed that when the speed is increased from 5 to $15 \mathrm{~km} / \mathrm{h}$, the wear indexes on the $B 1 W 1 R, B 1 W 2 R, B 2 W 1 R$ and $B 2 W 2 R$ wheels were slightly increased. Therefore, when subjected to an increase of speed from 5 to $15 \mathrm{~km} / \mathrm{h}$ on a curved track of $200 \mathrm{~m}$ radius, the additional wear on the high rail was evident but not significant.

\subsection{Effect of curve superelevation}

The curved track superelevation calculation is based on a main line track geometric design (ARTC 2015). The superelevation is calculated using the following equation:

$$
V=\sqrt{\frac{R \cdot E_{e}}{11.82}},
$$

where: $V$ is the speed $[\mathrm{km} / \mathrm{h}] ; R$ is the radius of curve $[\mathrm{m}] ; E_{e}$ is the equilibrium superelevation [mm]. Generally, the applied superelevation is obtained by subtracting the cant deficiency from the equilibrium superelevation. In a main line track geometric design (ARTC 2015), the cant deficiency is normally taken as $25 \mathrm{~mm}$ where track is designed for a controlled system with basically one operation and hence a choice of superelevation and cant deficiency. This requirement is in line with the principle that a level of positive deficiency is desirable to promote consistent vehicle tracking.

If the speed of $10 \mathrm{~km} / \mathrm{h}$ is considered for the calculation, the considered equilibrium superelevation will be $6,4,3$ and $2.5 \mathrm{~mm}$ for the curves with radii of 200,300 , 400 and $495 \mathrm{~m}$ respectively, which are much less than the cant deficiency. Therefore, the cant deficiency cannot be applied. The equilibrium superelevation is considered the same as the track superelevation without consideration of the cant deficiency.

The comparative wear indexes on the $200 \mathrm{~m}$ radius curve for the leading and trailing bogies with and without consideration of the track superelevation are provided in Figure 8. In Figure 8, the first group of wear indexes at $V=10 \mathrm{~km} / \mathrm{h}$ is from the simulations without consideration of track cant at any curve in the balloon loop. The remaining three groups at speeds of $V=5,10$ and $15 \mathrm{~km} / \mathrm{h}$ are from the simulations with consideration of track cants mentioned previously. From Figure 8, a)

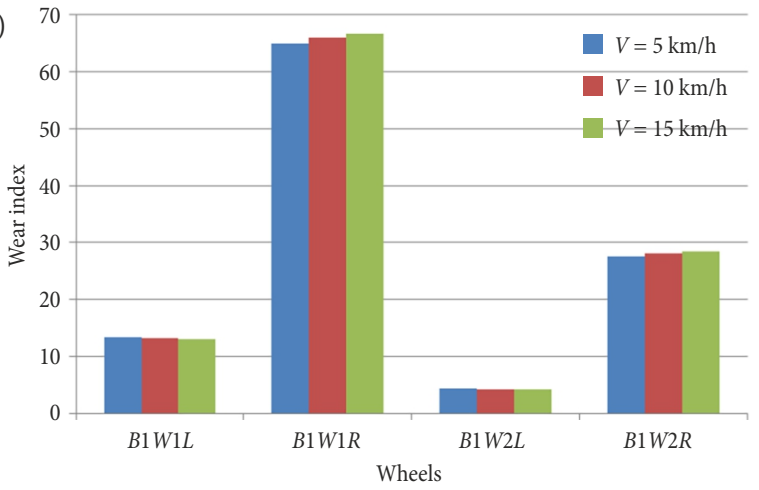

b)

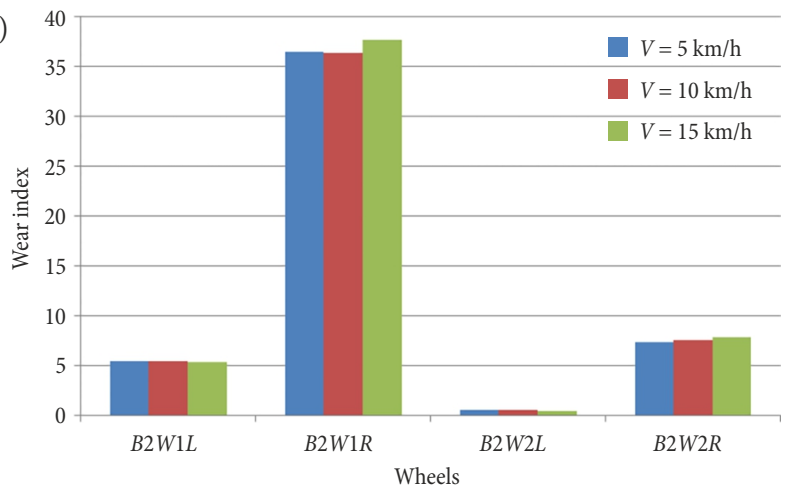

Figure 7. Wear indexes on all wheels on the $200 \mathrm{~m}$ radius curve at the speeds of 5,10 and $15 \mathrm{~km} / \mathrm{h}$ : $\mathrm{a}$ - on leading bogie; $\mathrm{b}$ - on trailing bogie 

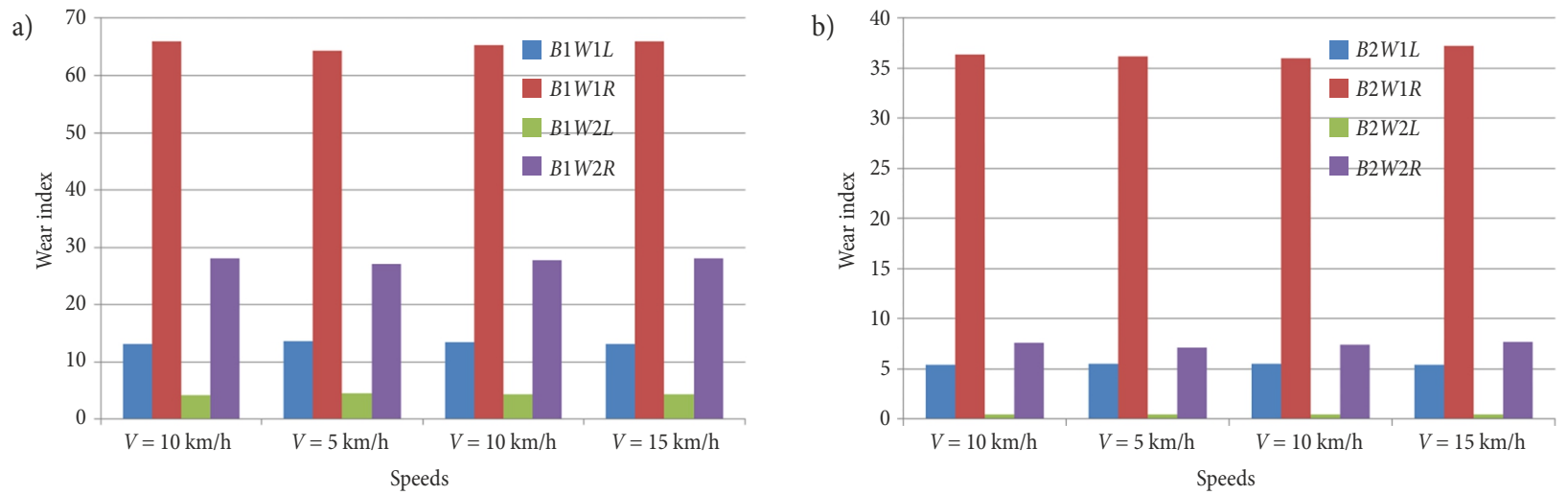

Figure 8. Wear indexes with consideration of the cant: $\mathrm{a}$ - on leading bogie; $\mathrm{b}$ - on trailing bogie

it can be seen that the wear indexes are not changed significantly after comparing two groups at $V=10 \mathrm{~km} / \mathrm{h}$. The change pattern of wear indexes as the speed increases is almost the same with and without consideration of track cants.

\subsection{Effect of wheel-rail contact friction coefficient}

It is well known, that a lower friction coefficient between wheel and rail results in less wheel-rail rolling contact wear. The reduction of friction coefficient can be realised by adding a lubrication medium, for example, water, oil, etc. Generally, on curved tracks there are two contact points on the high rail (the gauge corner and top), and one contact point on the low rail (on the top). The simulations are carried out at the speed of $15 \mathrm{~km} / \mathrm{h}$ with the friction coefficients of the three contact points being reduced from 0.5 (dry condition) to 0.1 (oil lubrication). Figure 9 shows the resulting wear indexes when using a friction coefficient of 0.2 .

Compared with Figure 5, it can be seen from Figure 9 that the all wear indexes were significantly decreased. For example, for the wheel B1W1R, the maximum wear index value of 66 in dry condition is reduced to about 33 with lubrication, resulting in a reduction of $50 \%$. In order to visually compare the overall effect of wheel-rail friction coefficients on the wheel-rail contact wear, the relationship between the sums of wear indexes on all wheelsets of both bogies on the balloon loop track is plotted and shown in Figure 10.

a)

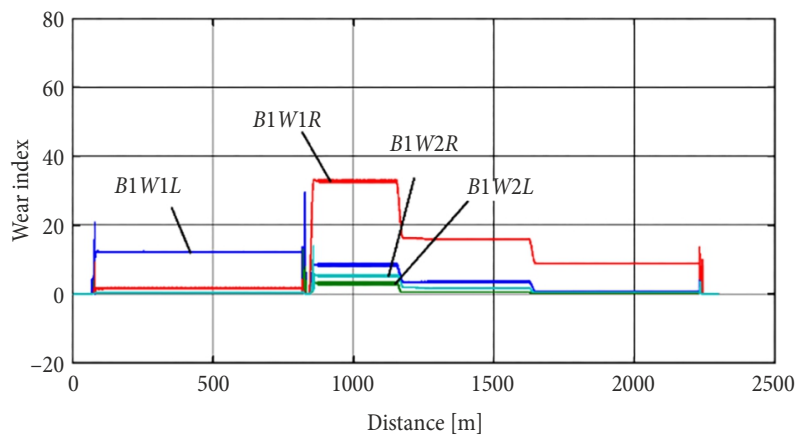

From Figure 10, the wear indexes are significantly reduced from the dry condition $(\mu=0.5)$ to the oily condition $(\mu=0.1)$ on all curves. For example, on the curve with radius of $200 \mathrm{~m}$, the wear index decreases from 162 to 20 . However, the reduction rate on a curve is slightly different from each other. From the curve radius of 200 , 300,400 and $495 \mathrm{~m}$, the reduction rates are 87.7, 92, 93.5 and $88.7 \%$ respectively. Among them, the reduction of wear index is the most effective on the curve with radius of $400 \mathrm{~m}$.

Further simulations were conducted under the same conditions except for a friction coefficient reduction to one contact point only and the other two points retained the previous dry condition $(\mu=0.5)$. For example, if the friction coefficient on the high rail gauge corner was reduced only, both the high and low rail tops are always kept in dry condition $(\mu=0.5)$. From the simulations, it was found that the friction coefficient reduction on the top of the high rail contributes the most reduction of wear index. Figure 11 shows the sum of wear indexes on all wheelsets of both bogies on the balloon loop track under the condition of friction coefficient being $\mu=0.1$ on the high rail top.

From Figure 11, the curve radii of 200, 300, 400 and $495 \mathrm{~m}$, the wear indexes were approximately 51, 23, 17 and 17 respectively. However, if the friction coefficients on these three contact points were reduced to $\mu=$ 0.1 , the wear indexes were approximately $20,8.5,5$ and 5 respectively, as shown in Figure 10.

b)

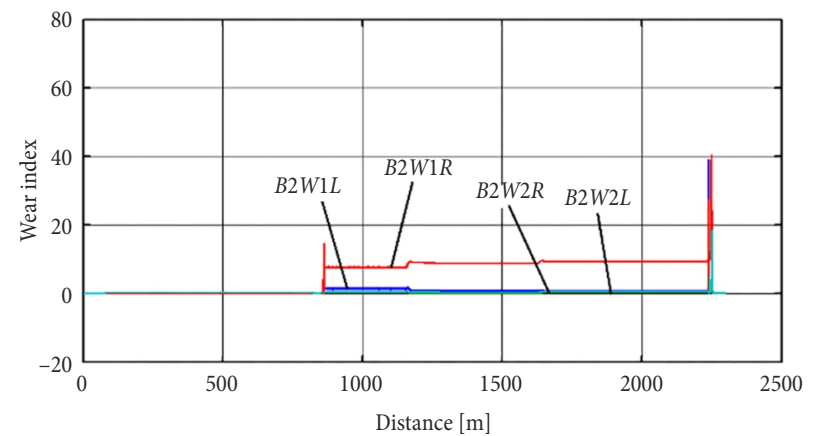

Figure 9. Wear indexes due to the wheel flange lubrication: $a$ - on leading bogie; $b$ - on trailing bogie 


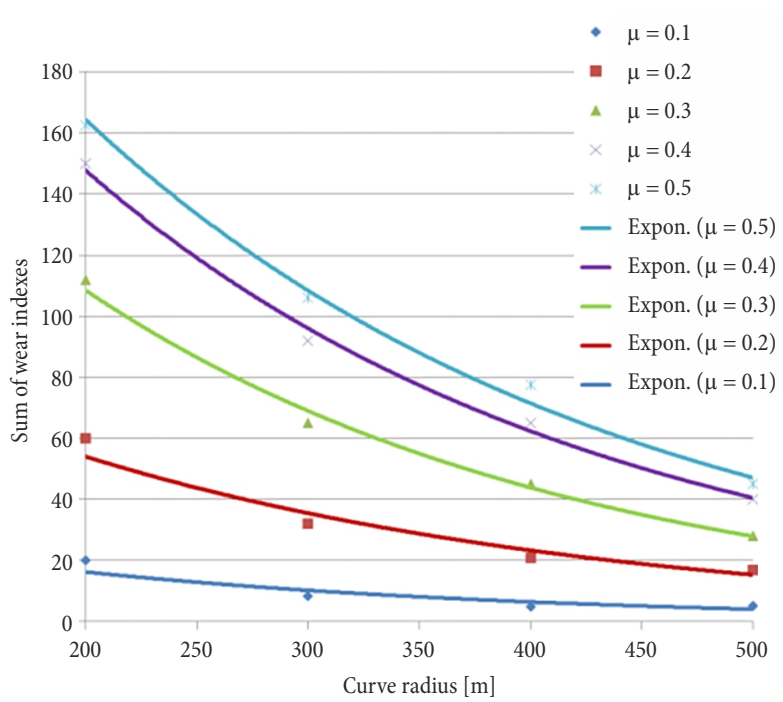

Figure 10. Sum of wear indexes

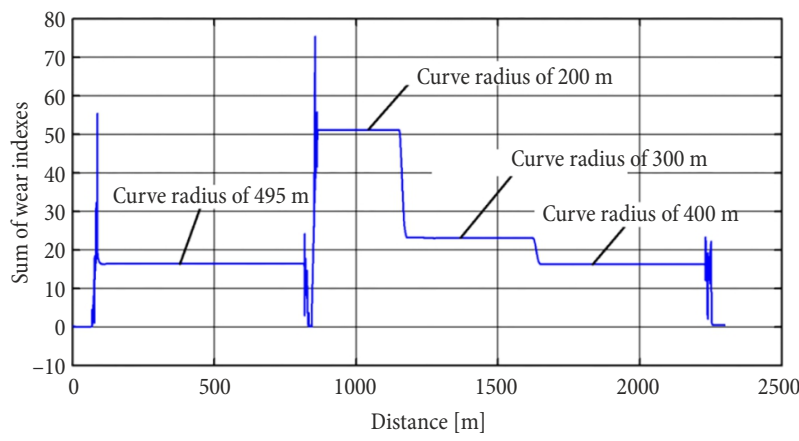

Figure 11. Sum of wear indexes with $\mu=0.1$ on the high rail top

\section{Discussion}

The simulations for wheel-rail wear in a hypothetical balloon loop track were conducted. The simulation results show that the leading bogie had more wheel-rail wear than the trailing bogie. Similarly, the leading wheelset in a bogie had more wheel-rail wear than the trailing wheelset. Generally, as the curved track radius reduces the severity of wheel-rail wear increases. The wheel-rail wear on the high rail is higher than that on the low rail. For example, on the high rail of curved track with a radius $R_{2}=200 \mathrm{~m}$, the $B 1 W 1 R$ had the highest wear index value of approximately 66 , the corresponding $T_{\gamma}$ was approximately $2768 \mathrm{~J} / \mathrm{m}$ (or N). Similar $T_{\gamma}$ values were also reported by Dukkipati, Swamy (2001).

In this paper, the wear index expressed in Equation (1) provided from the VAMPIRE ${ }^{\oplus}$ User Manual (Resonate Group Ltd. 2016) was used. When T $\gamma<160$, the wear index is calculated less than 0.8 , which is considered as mild wear, otherwise, it would be considered as severe wear with values $>160$. Equation (1) is used to evaluate whether wheel-rail wear is in a mild or severe situation. For these curved tracks, they would be always evaluated as severe wear.
For further investigation on predicting the wheel and rail worn profiles in a balloon loop track, it is obviously not suitable to use the wear index, however, some available wheel-rail wear functions (Tassini et al. 2010; Pombo et al. 2011) will be useful such as:

- the British Rail Research function (or Derby's equation) to calculate the material loss;

- the Royal Institute of Technology (KTH) function to calculate the volume of worn material;

- the University of Sheffield function to calculate the wear rate.

In the normal procedure for the design of curved track, the applied cant is determined by subtracting the cant deficiency from the equilibrium superelevation. However, in the balloon loop operation at the low speed less than $15 \mathrm{~km} / \mathrm{h}$, the calculated equilibrium superelevation is small and the cant deficiency cannot be applied. If the equilibrium superelevation is used, the wear indexes do not change significantly at the different speeds. From the simulations with an equilibrium superelevation, the wear on high rail is higher than that on the low rail. Whether or not the larger superelevation on a loop track is applied deserves attention.

\section{Conclusions}

A study on wheel-rail contact wear of slow speed balloon loop track was performed. A wagon dynamic system model has been applied and its dynamic behaviours were simulated using GENSYS package to interpret the wear conditions between the rail/wheel interfaces. The effects of some important parameters on the wheel-rail contact wear have also been conducted.

The simulated wear index on a hypothetical balloon loop track indicates that the track was subjected to very severe wear based on the wear index definition. The study shows that severe wear was mainly located on the gauge corner of the high rail of the curve.

The effect of curve radius on the wear index is significant, and with the reduction of curve radius, the wear index was increased exponentially. However, the change of speed under the low speed of $15 \mathrm{~km} / \mathrm{h}$ did not significantly affect the wheel-rail contact wear indexes. Furthermore, if the curves in the loop are considered with track superelevation calculated at the condition of speed $V=10 \mathrm{~km} / \mathrm{h}$, the wear indexes on the canted loop track do not significantly change compared with those on the loop track without superelevation.

The effect of wheel-rail contact friction coefficient to the wear index is also significant. If the friction coefficient is reduced from 0.5 (dry condition) to 0.1 (oily condition) on all wheel-rail contact points, the wear index will be decreased. For example, with $93.5 \%$ reduction on the curved track section with radius of $400 \mathrm{~m}$. Further simulations show that the friction coefficient on the top of the high rail plays a major role in overall reduction of wear index with speeds less than or equal to $15 \mathrm{~km} / \mathrm{h}$. 


\section{Acknowledgements}

The authors acknowledge the support of the Centre for Railway Engineering, Central Queensland University and the support from State Key Laboratory of Traction Power, Southwest Jiaotong University in the Open Projects: TPL1504, 'Study on heavy haul train and coupler system dynamics'.

The authors also acknowledge DEsolver for use of the GENSYS software in vehicle dynamics simulation.

\section{Funding}

This work was supported by the State Key Laboratory of Traction Power, Southwest Jiaotong University in the Open Projects: TPL1504, 'Study on heavy haul train and coupler system dynamics'.

\section{Disclosure statement}

Authors would declare that there are no any competing financial, professional, or personal interests from other parties.

\section{References}

ARTC. 2015. Track Geometry. Australian Rail Track Corporation (ARTC), Australia.

Braghin, F.; Lewis, R.; Dwyer-Joyce, R. S.; Bruni, S. 2006. A mathematical model to predict railway wheel profile evolution due to wear, Wear 261(11-12): 1253-1264. https://doi.org/10.1016/j.wear.2006.03.025

Chiddick, K. S.; Eadie, D. T. 1999. Wheel/rail friction management solutions, in 14th International Conference on Current Problems in Rail Vehicles: PRORAIL 99, 6-8 October 1999, Žilina, Slovakia.

Cuervo, P. A.; Santa, J. F; Toro, A. 2015. Correlations between wear mechanisms and rail grinding operations in a commercial railroad, Tribology International 82: 265-273. https://doi.org/10.1016/j.triboint.2014.06.025

DEsolver. 2017. GENSYS.1609 Reference Manual. AB DEsolver, Östersund, Sweden. Available from Internet: http://www. gensys.se

Donzella, G.; Faccoli, M.; Ghidini, A.; Mazzù, A.; Roberti, R. 2005. The competitive role of wear and RCF in a rail steel, Engineering Fracture Mechanics 72(2): 287-308. https://doi.org/10.1016/j.engfracmech.2004.04.011

Dukkipati, R. V.; Swamy, S. N. 2001. Non-linear steady-state curving analysis of some unconventional rail trucks, Mechanism and Machine Theory 36(4): 507-521. https://doi.org/10.1016/S0094-114X(00)00054-9

EMRAILS. 2016. $60 \mathrm{~kg}$ Rail. EMRAILS: The Australian Rail Stockist, Victoria, Australia. Available from Internet: https://www.emrails.com.au/our-products/rail/standardrail/60-kg-rail

ESR 0332:2010. WPR 2000 Wheel Profile. Engineering Standard, Rolling Stock, Australia. 8 p. Available from Internet: http://www.asa.transport.nsw.gov.au/sites/default/files/asa/ railcorp-legacy/disciplines/rollingstock/esr-0332.pdf

Harvey, R. F.; McEwen, I. J. 1986. The Relationship between Wear Number and Wheel/Rail Wear in the Laboratory and the Field. British Rail Research Report TM-VDY-001.

He, C.-G.; Zhou, G.-Y.; Wang, J.; Wen, G.; Wang, W.-J.; Liu, Q.-Y. 2014. Effect of curve radius of rail on rolling contact fatigue properties of wheel steel, Tribology 34(3): 257-261. (in Chinese).

Hernández, F. C. R.; Demas, N. G.; Davis, D. D.; Polycarpou, A. A.; Maal, L. 2007. Mechanical properties and wear performance of premium rail steels, Wear 263(1-6): 766-772. https://doi.org/10.1016/j.wear.2006.12.021

Ishida, M.; Aoki, F. 2004. Effect of lubrication on vehicle/track interaction, Quarterly Report of RTRI 45(3): 131-135. https://doi.org/10.2219/rtriqr.45.131

Johansson, A.; Pålsson, B.; Ekh, M.; Nielsen, J. C. O.; Ander, M. K. A.; Brouzoulis, J.; Kassa, E. 2011. Simulation of wheel-rail contact and damage in switches \& crossings, Wear 271(1-2): 472-481.

https://doi.org/10.1016/j.wear.2010.10.014

Pearce, T. G.; Sherratt, N. D. 1991. Prediction of wheel profile wear, Wear 144(1-2): 343-351. https://doi.org/10.1016/0043-1648(91)90025-P

Pombo, J.; Ambrósio, J.; Pereira, M.; Lewis, R.; Dwyer-Joyce, R.; Ariaudo, C.; Kuka, N. 2011. Development of a wear prediction tool for steel railway wheels using three alternative wear functions, Wear 271(1-2): 238-245. https://doi.org/10.1016/j.wear.2010.10.072

Remennikov, A. M.; Kaewunruen, S. 2008. A review of loading conditions for railway track structures due to train and track vertical interaction, Structural Control and Health Monitoring 15(2): 207-234. https://doi.org/10.1002/stc.227

Resonate Group Ltd. 2016. VAMPIRE ${ }^{\oplus}$ User Manual. Resonate Group Limited, Derby, UK. Available from Internet: http:// www.vampire-dynamics.com

Shevtsov, I. Y.; Markine, V. L.; Esveld, C. 2005. Optimal design of wheel profile for railway vehicles, Wear 258(7-8): 1022-1030. https://doi.org/10.1016/j.wear.2004.03.051

Spiryagin, M.; Sajjad, M.; Nielsen, D.; Sun, Y. Q.; Raman, D.; Chattopadhyay, G. 2014. Research methodology for evaluation of top-of-rail friction management in Australian heavy haul networks, Proceedings of the Institution of Mechanical Engineers, Part F: Journal of Rail and Rapid Transit 228(6): 631-641. https://doi.org/10.1177/0954409714539943

Spiryagin, M.; Wolfs, P.; Cole, C.; Spiryagin, V.; Sun, Y. Q.; McSweeney, T. 2016. Design and Simulation of Heavy Haul Locomotives and Trains. CRC Press. 459 p. https://doi.org/10.1201/9781315369792

Sun, Y. Q.; Cole, C.; Dhanasekar, M.; Thambiratnam, D. P. 2012. Modelling and analysis of the crush zone of a typical Australian passenger train, Vehicle System Dynamics: International Journal of Vehicle Mechanics and Mobility 50(7): 1137-1155. https://doi.org/10.1080/00423114.2012.656658

Sun, Y. Q.; Simson, S. 2008. Wagon-track modelling and parametric study on rail corrugation initiation due to wheel stick-slip process on curved track, Wear 265(9-10): 11931201. https://doi.org/10.1016/j.wear.2008.02.043

Sun, Y. Q.; Spiryagin, M.; Simson, S.; Cole, C. R.; Kreiser, D. 2011. Adequacy of modelling of friction wedge suspensions in three-piece bogies, in IAVSD 2011: 22nd International Symposium on Dynamics of Vehicles on Roads and Tracks, 14-19 August 2011, Manchester, UK, 1-6.

Tao, G.; Wang, H.; Zhao, X.; Du, X.; Wen, Z.; Guo, J.; Zhu, M. 2013. Research on wheel tread damage mechanism based on interaction of wheel and rail, Journal of Mechanical Engineering: 49(18): 23-29. (in Chinese).

Tassini, N.; Quost, X.; Lewis, R.; Dwyer-Joyce, R.; Ariaudo, C.; Kuka, N. 2010. A numerical model of twin disc test arrangement for the evaluation of railway wheel wear prediction methods, Wear 268(5-6): 660-667. https://doi.org/10.1016/j.wear.2009.11.003 
Telliskivi, T.; Olofsson, U. 2004. Wheel-rail wear simulation, Wear 257(11): 1145-1153.

https://doi.org/10.1016/j.wear.2004.07.017

Torstensson, P. T.; Nielsen, J. C. O. 2011. Simulation of dynamic vehicle-track interaction on small radius curves, Vehicle System Dynamics: International Journal of Vehicle Mechanics and Mobility 49(11): 1711-1732.

https://doi.org/10.1080/00423114.2010.499468

Waara, P.; Norrby, T.; Prakash, B. 2004, Tribochemical wear of rail steels lubricated with synthetic ester-based model lubricants, Tribology Letters 17(3): 561-568.

https://doi.org/10.1023/B:TRIL.0000044505.42373.0e

Wang, K.; Huang, C.; Zhai, W.; Liu, P.; Wang, S. 2014. Progress on wheel-rail dynamic performance of railway curve negotiation, Journal of Traffic and Transportation Engineering (English Edition) 1(3): 209-220. https://doi.org/10.1016/S2095-7564(15)30104-5

Zakharov, S.; Zharov, I. 2002. Simulation of mutual wheel/rail wear, Wear 253(1-2): 100-106.

https://doi.org/10.1016/S0043-1648(02)00088-1

Zhai, W.; Gao, J.; Liu, P.; Wang, K. 2014. Reducing rail side wear on heavy-haul railway curves based on wheel-rail dynamic interaction, Vehicle System Dynamics: International Journal of Vehicle Mechanics and Mobility 52(Suppl 1): 440454. https://doi.org/10.1080/00423114.2014.906633 